\title{
Crisis de la democracia representativa: alternativas participativas o democracia directa con medios electrónicos Crisis of representative democracy: participatory alternatives or direct democracy with electronic media
}

\author{
Antonio A. Martino \\ Universidades de Pisa (Italia) y El Salvador (Argentina) \\ aamartino@gmail.com
}

Recibido / received: 30/11/2017

Aceptado / accepted: 07/03/2018

DOI: https://doi.org/10.20318/eunomia.2018.4153

\begin{abstract}
Resumen
El artículo analiza la actual crisis de la democracia representativa criticando la tesis según la cual aquel país que instauraba una democracia y mantenía mínimos índices de solidez económica y social aseguraba su mantenimiento. A tal fin, inicia la explicación de la crisis de la democracia tout court y, después, va analizando las alternativas que se ofrecen a la democracia representativa. Así, aborda directamente la democracia directa para mostrar alguno de sus elementos más relevantes, sobre todo con medios electrónicos, y muestra posteriormente su reforzamiento.
\end{abstract}

\section{Palabras clave}

Democracia, representación, democracia directa, democracia participativa.

\begin{abstract}
The article presents the current crisis of representative democracy criticizing the thesis by which a country that reached democracy and maintained minimum rates of economic and social solidity had it insured. It explains first the crisis of democracy tout court and then analyzes the alternatives offered to representative democracy. It directly focuses on direct democracy to show important elements of it, above all with electronic means, to show later that elements of participatory democracy will be reinforced in the interim.
\end{abstract}

\section{Keywords}

Democracy, representation, direct democracy, participatory democracy. 
democracia directa?. 5. El gobierno abierto. 6. Las nuevas tecnologías y su interés en política. 7. La democracia líquida. 8. Algunos ejemplos.

9. La democracia directa. 10. Conclusiones.

Los ingleses se creen libres, pero se equivocan, porque sólo lo son durante las elecciones de los miembros del Parlamento; desde que éstas terminan vuelven a ser esclavos, no son nadie. Y en el corto tiempo de su libertad el uso que de ella hacen bien merece que la pierdan.

Jean Jacques Rousseau.

Si hubiera un pueblo de Dioses, se gobernaría democráticamente Jean-Jacques Rousseau, El contrato social, Libro III, Capítulo IV.

\section{1. ¿Crisis de la democracia?}

En 1977 escribía un artículo sobre la dictadura y constataba que había una tendencia importante en el mundo para pasar de sistemas totalitarios hacia sistemas democráticos (Martino, 1978: 273-294). A final de siglo, la tendencia era clara y los países democráticos eran mayoría -por primera vez- en el concierto internacional.

Hoy en día, el foco está puesto en las formas de gobierno de los países e, incluso, algunos regímenes totalitarios buscan disfrazarse como una democracia. Este es el caso de los países árabes del Norte de África o el de Corea del Norte o, también, se puede rescatar el caso de la República Popular China que tiene un régimen unipartidista.

Esto dio mucho material para estudiar y elaborar varias tesis. Una de las más afirmadas, la teoría de la consolidación democrática, sostiene que una vez que los países desarrollan instituciones democráticas, una sociedad civil robusta y cierto grado de riqueza su democracia está asegurada.

Con los movimientos que se van dando en muchos países -incluyendo los centrales- se diría que la teoría atraviesa un momento de crisis y merece la pena ocuparse de ella. Los más pesimistas se "preocupan".

Yascha Mounk ${ }^{1}$ se pasó los últimos años desafiando esta presunción fundamental de la política occidental: que una vez que un país se convierte en una democracia liberal, así permanecerá ${ }^{2}$. Su investigación sugiere lo contrario: que las democracias liberales alrededor del mundo pueden estar en serio riesgo. Mounk y Roberto Stefan $\mathrm{Foa}^{3}$ reunieron y analizaron datos sobre la fuerza de las democracias liberales y publicarán su conclusión en el número de enero de The Journal of Democracy. Actualmente, dijo Mounk, "las señales de advertencia están en rojo".

\footnotetext{
1 Yascha Mounk es un profesor alemán de teoría política en el Departamento del gobierno de la Universidad de Harvard, un Becario Postdoctoral de la Academia de transatlántico de la Fundación Marshall alemana y un compañero no residente en el programa de reforma política de los Estados Unidos.

${ }^{2}$ Yascha Monuk, “¿Cómo están usando los cleptócratas extranjeros las instituciones occidentales para proteger sus ganancias mal habidas?". Journal of Democracy, Enero 2018. En nuestro grupo de siete artículos sobre cleptocracia transnacional, los analistas examinan el aumento de las finanzas extraterritoriales, el enorme escándalo de 1 MDB de Malasia, cómo se comparan Rusia y China con el modelo cleptocrático, y más.

${ }^{3}$ Politólogo en la Universidad de Melbourne, en Australia. Publicaciones: "Legados de la regla colonial", Politics and Society, vol. 45 (2), 2017. STEFAN FOA R., INGLEHART R.F, KARABCHUK T. y PONARIN E. (2017), "Conjunto-Teoría de puntos y colapso de la sociedad: el caso de Rusia", Journal of Happiness Studies, Vol. 18 (3). STEFAN FOA R. y MOUNK Y. (2017), "Los signos de la desconsolidación", Revista Democracia, vol. 28 (1).
} 
La teoría de la consolidación democrática pareció sustentada por los sucesos globales. Los datos de Freedom House, una organización que monitorea la democracia y la libertad en el mundo, muestran que el número de países clasificados como "libres" aumentó de manera sostenida de mediados de los 70 hasta principios de los 2000. Sin embargo, desde 2005, el índice de Freedom House muestra que la libertad global cae año tras año. Estos autores desarrollaron una fórmula de tres factores para detectar si una democracia está aquejada de crisis, antes de que desarrolle síntomas inequívocos.

El primer factor es apoyo público: ¿qué tan importante creen los ciudadanos que sea que su país siga siendo democrático?

El segundo era la apertura pública a formas no democráticas de gobierno, como un régimen militar.

Y el tercer factor era si "partidos y movimientos anti sistema" estaban logrando apoyo entre el público.

Si estaba cayendo el apoyo por la democracia mientras las otras dos medidas estaban al alza, los investigadores catalogaban a ese país como "desconsolidándose"; el equivalente político a una fiebre baja que se presenta el día antes de la gripe. Por ejemplo, Venezuela disfrutó de las marcas más altas posibles en las medidas de Freedom House de derechos políticos y democracia en los 80 . Pero durante ese aparente periodo de estabilidad, Venezuela ya clasificaba como desconsolidándose en la prueba Mounk-Foa ${ }^{4}$.

De acuerdo con el sistema de detección temprana Mounk-Foa, las señales de desconsolidación democrática en Estados Unidos y muchas otras democracias liberales hoy son similares a las vistas en Venezuela antes de su crisis. En numerosos países, incluyendo Australia, Gran Bretaña, los Países Bajos, Nueva Zelanda, Suecia y Estados Unidos, se ha desplomado el porcentaje de personas que dice que es "esencial" vivir en una democracia, particularmente entre las generaciones jóvenes.

Hay un cuarto elemento que no tratan estos autores pero que está apareciendo en la sociedad: el cambio del paradigma del líder. Hasta ahora el líder era siempre una personalidad fuerte capaz de transmitir sus ideas y su entusiasmo a un número creciente de sujetos. Hoy el líder tiene más que ver con relaciones horizontales, mientras que en pasado eran sustancialmente verticales y tiene que ver con el uso de nuevas tecnologías.

Un quinto elemento de la crisis de la democracia es el ambiente de rabia que pulula en el mundo. El elemento "rabia" tampoco es nuevo. En su libro Elementos de derecho político ${ }^{5}$, Macarel, al hablar en el capítulo IV de la guerra civil, dice "Esta es una guerra de pasiones de furor y de rabia, destruye los principios del orden

\footnotetext{
${ }^{4}$ La crisis venezolana muestra, además un tema inquietante. En palabras de Loris Zanatta "los estériles debates de América Latina sobre Venezuela fotografían una región lacerada, atravesada por una cortina de hierro ideológica, dividida entre dos concepciones de la palabra "democracia" incompatibles entre ellas: la liberal, típica de los sistemas democráticos occidentales, que con el tiempo se ha extendido a muchos países que la habían rechazada, y la populista, basada en la creencia de un pueblo mítico investido de un derecho histórico a la hegemonía y al monopolio el poder", La Nación, 28 de junio 2017.

${ }^{5}$ MACAREL M.L.A. (1838), Elementos de derecho político, traducido por Félix Enciso Castrillon, II tomo, imprenta Yenes, de la calle Almudena, Madrid. Macarel fue miembro del Consejero de Estado Francés y agregado a la cátedra de Derecho Administrativo de París.
} 
social, rompe los lazos de la naturaleza y es una madre que devora sus propios hijos"6. Hoy el elemento rabia se ha vuelto un componente político y aparece en movimientos que no quieren llamarse "partidos" para no formar parte del sistema que critican. "El sistema canaliza la rabia de la sociedad a su favor" señala Emilio Triviño, del Movimiento de Ciudadanos hacia la República Constitucional (MCRC) ${ }^{7}$.

En efecto, la respuesta de una parte de la sociedad es "la rabia". Ira que se expresa en manifestaciones que escapan a las estructuras políticas convencionales, $\mathrm{o}$ en insultos en redes sociales y pasión por el escrache o el acoso a cualquiera. Para ese banco, el Brexit y el voto a Trump expresan esos sentimientos de la era de la "política de la ira".

\section{La crisis de la democracia representativa}

Debemos, brevemente, plantear una posible categorización indicando tres arquetipos de democracia y de participación: a) la democracia directa, b) la democracia representativa, c) la democracia participativa.

En términos generales y en palabras de Giovanni Sartori, «la democracia que debemos comprender es la democracia política destinada a reducir las múltiples voluntades de millones de personas a una jefatura única» ya que «la democracia política es aquella que opera en las peores condiciones posibles y no hay que pretender de una democracia a gran escala lo mismo que se puede esperar de una democracia en pequeña escala" (Sartori, 2012: 14).

Debo hacer una aclaración metodológica: soy un sistemista, es decir, uno de quienes sostienen que todo es un sistema o una parte de él. En particular, un sistemista cognitivista, entendiendo por tal una concepción en la que el sistema no es un "afuera" o un "estar alli". "Mientras seamos capaces de observar y toparnos con esas partes, su sistematicidad surge de relaciones, las cuales son abstractas... experimentamos y hablamos de sistemas, pero no nos topamos con ellos allá afuera. Les damos nombres y al hacerlo les proporcionamos existencia" (Espejo y Reyes, 2016: 7). Dicho de otro modo un sistema es una construcción mental que tiene un correlato objetivo en el mundo, pero no hay algo así como un sistema objeto y un observador externo (Maturana y Varela, 1992).

Esto es particularmente importante en los sistemas de los cuales formamos parte. Sus bordes, sus límites, sus componentes y sus relaciones tienen que ver con la concepción mental con la que se los aborda aunque tengan -como dijimos - un correlato objetivo. Tanto la concepción de la democracia, como los arquetipos de democracia representativa, directa y participativa tienen un correlato objetivo pero son nuestras construcciones mentales que no necesariamente coinciden, por eso es importante distinguir los tipos y los arquetipos y las respectivas concepciones que manejamos ${ }^{8}$.

La democracia representativa está en crisis. En primer lugar, por la crisis de los partidos políticos pero, más allá, por una falta de confianza por parte de la ciudadanía en las maniobras políticas en general.

Por un lado, las groseras desmentidas ciudadanas a las apuestas de políticos avezados: El fracaso del referéndum pedido por David William

\footnotetext{
6 ídem, p. 206.

${ }^{7}$ El Sol Digital, 10 octubre, 2017. Emilio Triviño, abogado, vive y trabaja en Marbella.

${ }^{8}$ Esto se verá mejor en las conclusiones.
} 
Donald Cameron con el Brexit; el rechazo a los Acuerdos de Cuba de la pacificación colombiana pedida por Juan Manuel Santos, presidente de Colombia; la derrota de Hillary Clinton en USA a favor de Donald Trump; la pérdida del referéndum sobre la reforma política de Matteo Renzi ${ }^{9}$.

Por otro, el avance de la anti-política: la aparición de movimientos antiestablishment en el mundo se está volviendo una costumbre. Tal vez desde Syriza en Grecia, con el triunfo de lo que parecía un frente populista antieuropeo y anti-banca internacional, se desmantelaba un gobierno completo, además de un supuesto régimen de acuerdos y negociación.

Hemos visto el creciente peso que Podemos gana en España, ahora frente al escenario de nuevos comicios generales, donde la fuerza popular de izquierda ha concretado ya una alianza con Izquierda Unida, conformando el primer pacto electoral para las siguientes elecciones ${ }^{10}$. La propia elección de Trump con la ropa de contestación a la política tradicional y el surgimiento de muchos "movimientos" que no quieren llamarse "partidos" justamente para destacar que son "anti políticos"11.

El triunfo del capital: en nuestra época, la concentración de la riqueza es la mayor que conoce la historia humana. Desde una óptica economicista se podría decir que esta observación inicial es una obviedad, porque la concentración de la riqueza es un resultado permanente del capitalismo y, por lo tanto, cada época tendría que superar a la anterior en esa materia. Sin embargo, cuando hablamos de "nuestra época" nos referimos a un período histórico relativamente breve: el que va desde la crisis económica mundial de los años setenta del siglo pasado a nuestros días; una época de brutal acumulación de recursos en una parte ínfima de la población mundial. En esos años, se produce una auto revolución capitalista: de la crisis emerge una nueva configuración social; el capital le gana una batalla fundamental a escala mundial al trabajo. El deslizamiento a saltos de una economía industrial a una economía financiera-informacional y de servicios produce el doble efecto de construir una nueva élite capitalista -acaso la primera que merezca llamarse "global"- y de debilitar material e idealmente al gran sujeto social del siglo $X X$, la clase obrera.

Se afirma también que hay una percepción de competencia total, cada vez más acelerada, sobre terrenos desiguales; una guerra de todos contra todos, lo cual produce un tremendo incremento en odio mutuo y una irritabilidad universal. "Si la gente se siente frustrada triunfa la demagogia", el anarquismo de los desheredados y de los que se sienten superfluos, el nihilismo del lobo solitario. Emergen individuos desafectados, globalmente, que realizan actos de extrema violencia contra sus supuestos enemigos. Para ellos la violencia lo es todo pues carecen de una visión de una realidad política alternativa. Hay quienes caracterizan estas expresiones

\footnotetext{
${ }^{9}$ La afluencia a las urnas de solo el 46\% del electorado en las elecciones políticas de junio 2017 en Italia.

${ }^{10}$ Por Rosendo Fraga, NuevaMayoria.com, 17 de junio de 2016: "La segunda vuelta de las elecciones locales de Italia adquieren significación más allá de sus fronteras por la posibilidad de crecimiento de la llamada "anti-política"'. En las elecciones del 4 de marzo último aumentó ligeramente la participación pero ganó la "anti política" con votos al Movimiento 5 estrellas y a la Liga, que además son anti europeístas. Ningún partido tiene la mayoría y si se logra un gobierno será de coalición o de ingeniería del Presidente de la Republica".

${ }^{11}$ La historia no es nueva, para evocar tiempos modernos empecemos por Berlusconi quien después de la causa "Cusani" (mani pulite) se presentó, ante la ruina de los dos partidos centrales más importantes: la Democracia Cristiana y el Partido Socialista, como el no político que salvaría la política. Pero la política es como el rey Midas: todo lo que toca lo transforma en político y Berlusconi fue ( $\mathrm{y}$ es aun) un político condenado por corrupción que sigue contando en la política italiana.
} 
como una guerra civil global o como una jihad global, donde las organizaciones extremistas encuentran sus reclutas entre los jóvenes desempleados e inempleables, fácilmente y en todas partes ${ }^{12}$.

Es de estos tiempos la acción del gobierno húngaro encabezado por Fidesz que lanzó una campaña nacional de anuncios publicitarios y televisivos que recuerda las horas más oscuras de Europa. La campaña utiliza una imagen de un sonriente George Soros con el lema "No permitamos a Soros tener la última risa"13.

\section{Soluciones posibles}

Frente a esta crisis de la democracia representativa quedan sustancialmente dos alternativas: 1. Profundización de la democracia participativa con miras a una democracia deliberativa o 2. Alternativa de democracia directa con uso de nuevas tecnologías.

Voy a partir del camino más difícil, el de la democracia directa, para describir también los otros elementos de una democracia participativa ${ }^{14}$.

El punto 2 Alternativa de democracia directa con uso de nuevas tecnologías pienso desarrollarlo a continuación, advirtiendo que también me referiré a las democracias participativas o deliberativas pues no se trata de un aut entre democracia representativa y democracia directa: hay una serie de instrumentos intermedios que existen y, seguramente, se ampliará su uso, en el futuro inmediato.

El tema no solo es nacional sino también supranacional. En Europa existe un "Movimiento cambiemos la ruta de Europa" que en la preparación de su reunión italiana el 14 de septiembre expresa: "Para responder al neo-proteccionismo USA, al nacionalismo ruso y a la transformación en la red de los poderes globales, la reapertura de la obra europea aparece, así pues, necesaria a fin de dotar a la Unión Europea de los poderes y de los instrumentos necesarios para desarrollar un papel autónomo de actor a nivel planetario que contribuya a dirigir un nuevo periodo en el gobierno de la interdependencia marcado por un desarrollo equilibrado y sostenible de la distensión y del respeto de la dignidad humana. No se excluye ninguna variante de la construcción institucional, sea tanto del punto de vista del método como del contenido del proyecto. En este marco el Movimiento europeo en Italia está convencido de que los países de la Eurozona y aquellos que deseen entrar a formar parte de la misma son llamados a constituir la vanguardia de una más

\footnotetext{
12 Ver MISHRA P. (2017), La edad de la ira, Galaxia Gutemberg, Barcelona. Ocurre cuando, por primera vez en la historia, casi todas las personas del planeta tienen un presente común y hay una sensación de que todo está fuera de control, que elites arrogantes y fraudulentas humillan a la gente, sensación que traspasa las líneas de las nacionalidades, las religiones y las razas. Surge, entonces, un mesianismo revolucionario impulsado por el deseo de lograr una solución inmediata y definitiva, el cual denuncia la distribución muy desigual de los beneficios económicos que genera el capitalismo.

${ }^{13}$ La posición actual de Soros sobre la migración es que la comunidad internacional debería prestar más apoyo a los países en desarrollo que acogen hoy al $89 \%$ de los refugiados y que Europa debe aceptar a varios cientos de miles de refugiados que han sido sometidos a un proceso ordenado de investigación y reasentamiento. Cree que los solicitantes de asilo cualificados no deberían arriesgar sus vidas cruzando el Mediterráneo para alcanzar la seguridad. Ver https://www.economist.com/news/united-states/21722176-attacked-politicians-washington-skopjegeorge-soros-runs-gauntlet

${ }^{4}$ El punto 1 o sea la Democracia participativa lo desarrolla magníficamente bien DALLA VIA A. con su La democracia directa: entre la utopía y la anarquía (no obstante el titulo), Instituto de Derecho Constitucional de la Academia de Derecho y Ciencias Sociales de Buenos Aires. Tanto el trabajo de Dalla Via cuanto este que presento se originaron en las reuniones del Instituto en Buenos Aires y allí constan ambos trabajos.
} 
completa integración política para construir una Unió federal ${ }^{15}$. Con una reflexión suplementaria: existe la creencia que los ciudadanos se ocupan mucho de política pues hablan mucho de ella. Creencia errónea ${ }^{16}$. A los ciudadanos les encanta hablar de política, alabando a unos y criticando a otros y delineando algún mundo medianamente imposible. Pero al momento de "ocuparse de política" son pocos los que quedan en el campo ${ }^{17}$.

En este momento es difícil saber si la democracia directa es posible en un tiempo previsible pero es cierto que muchos acontecimientos van llevando hacia ella.

\section{Soluciones posibles}

El segundo cuerno de la alternativa es la salida a la democracia directa. Magnífica idea en comunidades pequeñas pero dificilísima en las comunidades actuales nacionales y supranacionales.

En este momento es difícil saber si la democracia directa es posible en un tiempo previsible, pero es cierto que muchos acontecimientos van llevando hacia ella. Trataré de ir recorriendo un camino que, en mi concepción, llevará a la democracia directa, pero no sabría indicar tiempos.

\section{El gobierno abierto}

En muchas partes del mundo se abre paso la idea de presentar o requerir un gobierno abierto, esto es, una nueva forma de gestión pública; una nueva relación entre los ciudadanos y sus gobernantes. Es una filosofía de gobierno que plantea una gestión pública transparente y colaborativa, a partir de la disponibilidad de la información completa, veraz y suficiente, para que los ciudadanos puedan tomar parte en las decisiones de gobierno de manera idónea y efectiva. Todo basado en una relación constante de ida y vuelta de información entre el Estado y los ciudadanos.

Los comienzos de la Administración Obama en los EE.UU., y sus esfuerzos por modernizar la administración federal, significaron el inicio del redescubrimiento del concepto gobierno abierto (open government) dentro del sector público en todo el mundo. En este sentido, el Memorándum for Transparency and Open Government (21 de enero de 2009), incorporó esta cuestión como una prioridad política de primer

\footnotetext{
$15 \mathrm{Y}$ agrega, por si hubiese dudas: "para responder al neoproteccionismo estadounidense, el nacionalismo ruso y la transformación de la red de poder global, la reapertura del astillero europeo es necesaria para proporcionar a la Unión Europea los poderes e instrumentos necesarios para desempeñar un papel autónomo como actor en nivel planetario para ayudar a comenzar un nuevo ciclo en la gobernanza de la interdependencia marcada por el desarrollo equilibrado y sostenible, la detente y el respeto por la dignidad humana. No debe excluirse ninguna variante de la construcción institucional, tanto desde el punto de vista del método como del contenido del proyecto. En este contexto, el Movimiento Europeo en Italia está convencido de que los países de la eurozona y aquellos que desean unirse a ella están llamados a ser la vanguardia de una integración política más completa para crear una comunidad federal".

${ }^{16}$ En reciente investigación el consultor Hugo Haime reveló que al $50 \%$ de los electores bonaerenses "no le interesa votar". ¿A qué se debe este desinterés? ¿Quiénes son los responsables: los partidos, sus (pobres) propuestas? Algunos dicen que no es que no les interese el sistema o la democracia o la república o el futuro, sino que, simplemente, no están pensando en ello.

17 Probablemente por eso en el viejo partido comunista italiano existía la costumbre de pedirle a los aspirantes a afiliados que repartieran casa por casa el diario Unità. Un viejo dirigente sostenía "quien no está dispuesto a repartir el diario mucho menos lo estará cuando el partido lo necesite".
} 
orden en torno a tres principios claves: colaboración, transparencia y participación.

Gobierno abierto y profundización de la democracia son dos caras de la misma moneda ya que las medidas para implementarlo constituyen una nueva forma de aproximarse a los ciudadanos, una revolución en la forma de utilizar la información de las administraciones públicas o, incluso, una plataforma en la que los ciudadanos se convierten en los verdaderos protagonistas de la democracia. Cuando hablamos de gobierno abierto nos referimos al acceso y la libertad de información, la protección de datos, la reforma de las leyes sobre secretos oficiales y la necesidad, en una democracia consolidada, de poder obtener información útil y accesible sobre las actividades gubernamentales.

La teoría de la democracia participativa aparece como un intento de combinar adecuadamente el principio de representación con el incremento de la participación política de los ciudadanos. Podemos considerar que la teoría de la democracia participativa es un modelo normativo puro y dentro del amplio espectro de enfoques que pueden ser identificados como tal. Las características básicas que subyacen en la misma son el fomento a la participación directa de los ciudadanos en el gobierno y la deliberación en la formación de la opinión política.

Desde hace una década, y sobre todo a raíz de la crisis económica mundial que comienza en 2008 , han aumentado las presiones para que los gobiernos y sus administraciones públicas se abran al escrutinio público, sean más accesibles y sensibles a las demandas y necesidades de los ciudadanos, y respondan por la confianza política otorgada para gestionar la cosa pública. El debate sobre del tipo de gobierno e instituciones públicas que son necesarias para asumir los retos que impone el siglo XXI es la continuación de una reflexión permanente por adecuar la arquitectura institucional y política, la reforma del Estado y los procesos de modernización de la gestión pública, que se han intensificado en los últimas dos décadas.

Sin embargo y dado el reconocido fracaso de diversos modelos de reforma y la contradictoria evidencia vinculada a los resultados de las recetas aplicadas bajo el paradigma de la Nueva Gestión Pública (NGP), ha surgido un nuevo movimiento en cuya base encontramos un fuerte cuestionamiento a la forma en que se trabajan los asuntos públicos, que pone de relieve el incontestable fenómeno del uso intensivo de las tecnologías de información y comunicación (TIC) y de las redes sociales (o Web 4.0$)^{18}$, que promueve una activa y comprometida participación de la ciudadanía

\footnotetext{
${ }^{18}$ Uso este término clásico para quienes se ocupan de nuevas tecnologías, para los menos avezados baste decir que el termino web 0.2 o Web Social comprende aquellos sitios web que facilitan el compartir información, la interoperabilidad, el diseño centrado en el usuario y la colaboración en la World Wide Web. Un sitio Web 2.0 permite a los usuarios interactuar y colaborar entre sí, como creadores de contenido, en una comunidad virtual. Ejemplos de la Web 2.0 son las comunidades web, los servicios web, las aplicaciones Web, los servicios de red social, los servicios de alojamiento de videos. La web 3.0 son aplicaciones web conectándose entre sí, a fin de enriquecer la experiencia de las personas, haciendo uso de formatos especializados que amplían la información y sugiere otra, esto proporciona autonomía respecto del navegador y construcción de la Web Semántica. Web 3.0 también ha sido utilizada para describir el camino evolutivo de la red que conduce a la inteligencia artificial. Algunos escépticos lo ven como una visión inalcanzable. Sin embargo, compañías como IBM y Google están implementando nuevas tecnologías que cosechan información sorprendente, como el hecho de hacer predicciones de canciones que serán un éxito, tomando como base información de las webs de música. El turno de avanzar hacia la web 4.0 en la que el sistema operativo establecido en la web cobre protagonismo, hacia una Web Ubicua, donde el objetivo primordial será el de unir las inteligencias donde tanto las personas como las cosas se comuniquen entre sí para generar la toma de decisiones. Ya se espera que haya agentes en la Web que conozcan, aprendan y razonen como lo hacemos las personas. Hay ejemplos como ya el sistema Watson de IBM que comprende lenguaje natural y tiene la capacidad de aprender.
} 
y que, finalmente, presiona a los gobiernos e instituciones públicas a ser más transparentes, facilitar el acceso a la información que poseen, y a guiarse por nuevos códigos de conducta en cuyo trasfondo residen las nociones de "Buen Gobierno".

Para la OCDE el término ha evolucionado desde una mirada basada en tres dimensiones relevantes que apelan a contar con una Administración Pública transparente, accesible y receptiva (OCDE, 2006) $)^{19}$, a un enfoque donde se le considera como plataforma para resolver cómo el gobierno puede trabajar con la sociedad y los individuos para co-crear valor público (OCDE, 2010) ${ }^{20}$.

Algunos de los ejemplos más conocidos son los que ofrecen portales web como http://www.wheredidmytaxgo.co.uk/ o http://flyontime.us/ en los que se abordan experiencias ligadas a la filosofía del open government. En el primer caso, se ofrece la oportunidad a los contribuyentes británicos de conocer el destino de sus impuestos, incorporando en la aplicación unos datos básicos relativos a la renta. En el segundo, la experiencia resulta más llamativa todavía, en la medida que la aplicación desarrollada permite cruzar datos procedentes de dos agencias públicas diferentes, sobre el nivel de puntualidad de todas las compañías aéreas que operan en todos los aeropuertos de los Estados Unidos, con los datos sobre las condiciones climatológicas. El resultado es la posibilidad de conocer la hora estimada de llegada de un vuelo en el futuro, teniendo en cuenta las condiciones climatológicas previstas para el día y hora de llegada. En los dos casos, los datos puestos a disposición por las administraciones públicas resultan el sustrato necesario que facilita la posterior innovación social. Desde un punto de vista práctico, la puesta en marcha de la iniciativa Open Government Partnership ha puesto de relieve el interés y viralidad de este tipo de iniciativas dentro de los gobiernos a nivel global. La declaración original fue planteada el 20 de septiembre de 2011 y establece algunas ideas clave ligadas a la apertura y rendición de cuentas dentro del sector público ${ }^{21}$.

Es un nuevo paradigma de gobierno. $Y$ se basa en tres principios: transparencia, participación ciudadana y rendición de cuentas. El ex presidente de los Estados Unidos, Barack Obama fue, como apuntaba más arriba, uno de los pioneros cuando en enero de 2009 realizó la siguiente declaración: "Mi administración está comprometida con la creación de un nivel sin precedentes de apertura en el gobierno. Vamos a trabajar juntos para asegurar la confianza pública y establecer un sistema de transparencia, participación pública y colaboración".

\section{Las nuevas tecnologías y su interés en política}

Las nuevas tecnologías han irrumpido con fuerza en la vida cotidiana desde el uso de celulares hasta la difusión de las redes sociales en lo que se denomina TICs. Obviamente la política no podía quedar fuera. Aunque el periodo de uso haya sido breve hasta ahora, ya podemos decir que la penetración de la telefonía móvil y

\footnotetext{
${ }^{19}$ El trabajo de la OCDE estadístico 2013-2014:

http://www.oecd.org/centrodemexico/laocde/El\%20trabajo\%20estad\%C3\%ADstico\%20de\%20la\%20OC DE\%20EBOOK.pdf

${ }^{20}$ Evaluación de la OCDE del sector de las nuevas empresas basadas en el conocimiento: http://www.oecd.org/centrodemexico/Evaluaci\%C3\%B3n_de_la_OCDE_del_sector_de_las_nuevas_em presas_\%20IMPRENTA-1.pdf

21 "Reconocemos que el acceso equitativo y asequible a la tecnología es un desafío, y nos comprometemos a buscar una mayor conectividad en línea y móvil, a la vez que identificamos y promovemos el uso de mecanismos alternativos para el compromiso cívico. Nos comprometemos a involucrar a la sociedad civil y la comunidad empresarial para identificar prácticas efectivas y enfoques innovadores para aprovechar las nuevas tecnologías para empoderar a las personas y la transparencia remota en el gobierno", Open Government Partnership, 2011.
} 
las nuevas tecnologías es importante. La e-administración avanza con relación a las empresas y menos con respecto a los ciudadanos. Pero avanza.

Las instituciones políticas tratan de usar las nuevas tecnologías pues allí están las nuevas formas rápidas de dar mensajes y recibir respuestas. Las usan para reformular su estructura y reforzar el poder, pero no pueden eliminar los hándicaps de la comunicación y del poder. Las nuevas tecnologías tienen dos caminos en política: uno, más sencillo, es el de reforzar los medios actuales de la democracia representativa; el otro, más lejano y complicado, el de favorecer una nueva manera de hacer política.

Internet y la democracia se encuentran y chocan entre la teoría y la práctica, al tiempo que socava los viejos regímenes políticos; de hecho, empuja hacia la realización de una inversión directa. Todavía estamos lejos de una definición de la democracia como el proceso de elaboración de políticas, en la que los gobernantes, consideradas iguales en lo político, controlable y reemplazable, demuestran receptiva a las preferencias de los gobernados.

La receptividad es la función resaltada por Dahl (1994) en la definición de la democracia como sistema político que tiene la capacidad de responder a las necesidades de los ciudadanos. Desde aquí, también, se plantea lo que el propio Dahl ha llamado dilema democrático: “...para hacer crecer el tamaño de la póliza, disminuye el control de los ciudadanos sobre el mismo, por lo que la democracia Estado-nación parece que tiene que correr la misma suerte que la democracia de las ciudades-estado" (Dahl, 1994: 25).

A partir de la democracia directa, en el modelo del ágora de Atenas, donde se colocan los políticos y la gente en el mismo nivel, se ha producido una intervención inmediata de la comunidad en cada una de resoluciones específicas a través de los instrumentos de referéndum, la iniciativa popular, los referéndums confirmatorio o revocatorio. La democracia representativa, en la que ahora tiene una intervención indirecta las personas, se ha inclinado hacia la democracia directa. En las deliberaciones, las cuales, a través de la libre expresión de sus votos, se produce la elección de los titulares de los órganos del estado supremo al que se le asigna la tarea de actuar como su representante. Esto es autogobierno, el truco consiste en orientar a las personas no expertas en un tema sobre otras más expertas, para llegar a través del establecimiento de una democracia electrónica. En ella la mayor velocidad de la información, el creciente deseo de una política más accesible a todos, y la cada vez mayor decepción de los ciudadanos en relación con acciones de los políticos, juegan un papel central en la fase de proposición y el procesamiento de las informaciones.

En su libro La democracia fuerte. Política de participación para una nueva era. B. Barber establece que "las democracias eficaces necesitan grandes ciudadanos. Somos libres sólo si somos ciudadanos y nuestra libertad y nuestra igualdad duran todo el tiempo que dure nuestra ciudadanía (...) Los ciudadanos definitivamente no nacen, sino que se convierten en tales, como resultado de la educación cívica y el compromiso político en un estado libre" (1984: 247). De acuerdo con Barber, únicamente la democracia fuerte es capaz de mantener viva la democracia ya que no está garantizada por los líderes políticos, sino por ciudadanos competentes y responsables. La democracia fuerte se centra la atención en la capacidad educativa y la libertad que su ejercicio político puede y debe tener la ciudadanía. 
Esto se hace eco de McLuhan (1964). La formulación de políticas que se hacen más acuciantes "con el aumento de la velocidad de la difusión de la información, la tendencia en la voluntad política para alejarse de la representación y la autoridad concedida a los elegidos, para acercarse a un lugar implicado dirigido a la comunidad en las decisiones del gobierno".

Por último, la República Electrónica se realizará cuando se vuelvan a dibujar las instituciones políticas y se replanteen todos los mecanismos políticos que no funcionan y que contribuyen a la creciente frustración de la gente hacia la política. En otras palabras, los estudios sobre la política y el gobierno tendrán que cambiar su orientación y cuestionarán no sólo en la calidad de la dirección política (de arriba hacia abajo) también, y sobre todo, en la calidad de la ciudadanía (de abajo arriba).

Norberto Bobbio, lógicamente no haciendo referencia a la red digital, ya en el año 1985 entendió que la democracias directa y representativa no eran suficientes e indicó que "el proceso de ampliación de la democracia en la sociedad contemporánea no se presenta solamente a través de la integración de la democracia representativa con la democracia directa, sino también, y sobre todo, mediante la extensión de la democratización, entendida como institución y ejercicio de procedimientos que permiten la participación de los interesados en las deliberaciones de un cuerpo colectivo, en cuerpos diferentes de los políticos" (1989: 218).

\section{La democracia liquida ${ }^{22}$}

La sociedad civil demanda condiciones más participativas y deliberativas en el mundo institucional y social; la idea es promover políticas deliberativas que lleven a la comunidad a tomar decisiones ${ }^{23}$.

Al más general concepto de democracia participativa y "que tiene entre sus efectos la desconexión entre gobernantes y gobernados, la ruptura del vínculo representativo entre representados y representantes y el distanciamiento del ciudadano de la vida pública" (Ramírez Nárdiz, 2014: 196), se suma el que se conoce como "democracia líquida" cuya participación se despliega a través de las nuevas tecnologías y más en concreto mediante internet.

En los diferentes portales internet que tratan la idea de democracia liquida, no se encuentra una definición univoca de esta nueva y posible experiencia. A lo largo de este trabajo indicaré los elementos que caracterizan la democracia líquida, mejor aún la remisión que hice a un trabajo anterior. La democracia liquida es la suma de la democracia directa y participativa que se desarrolla a través de nuevas tecnologías que logran superar el límite representativo al que la ciudadanía le tiene rechazo y que identifican con la actual clase política.

En este sentido entonces podemos decir que las dos figuras pueden ser compatibles y complementarias, es decir, la democracia participativa-directa engloba la democracia líquida como herramienta técnica para construir una política participativa.

\footnotetext{
22 Me he ocupado del tema en el libro Legislación y Digesto, Eudeba, Buenos Aires, 2014 y allí me remito para un tratamiento más amplio.

${ }^{23}$ CÁRDENAS GARCÍA, J., "Democracia interna en los partidos y democracia participativa", [En línea]: www.juridicas.unam.mx/publica/librev/rev/derestas/cont/1/.../ens8.pdf, pág. 151.
} 
Según el portal web «democracialiquida.org», se trata de que a cada ciudadano se le reconozca la posibilidad de votar las decisiones y realizar propuestas, mediante su voto o cediéndolo a un representante para aquellas decisiones en las que prefiere no participar. En una democracia líquida, "Ios ciudadanos que desean implicarse en la vida política, pueden hacerlo, y los que optan para no involucrarse, pueden acudir a representantes. Así mismo, cualquier ciudadano o grupo de ciudadanos puede crear un representante virtual, que publicará su intención de voto en nombre del partido político o corriente de opinión a la que representa"24.

Los pilares de la democracia líquida son entonces fundamentalmente dos: la delegación del voto y la construcción de un Parlamento Virtual. Sin embargo, estos dos elementos no pueden tener aplicación si previamente no identificamos el escenario en que deberían impulsarse. La preocupación no reside en la utilización de internet para participar en la política de un país -los avances tecnológicos son imparables y más temprano que tarde el Parlamento virtual si no será una realidad, por lo menos será una posibilidad concreta-; más bien se levantan algunas inquietudes sobre quién y cómo se gestionarán, filtrarán y utilizarán las informaciones que almacenadas en la sociedad de la información se catapultan en la sociedad del conocimiento.

Los partidarios de la democracia líquida identifican la delegación del voto (y la delegación del voto digital) como uno de los puntos cardinales de la política democrática digital. Técnicamente, se trata de confiar el voto a un representante experto por cada materia de actuación. Se asiste entonces a una modalidad que, en sus características jurídicas y generales, identifica un mandatario que cumple con instrucciones (Sartori, 1989: 142). Esta técnica no menoscaba la participación directa, es decir, el ciudadano recurrirá a la delegación sólo en los casos que no tiene interés o competencia para expresarse conscientemente sobre un tema concreto. Este sistema además incluye la "delegación transitiva" donde el nombrado representante puede delegar a otros representantes estableciéndose así verdaderas cadenas de confianza que canalizan los votos ${ }^{25}$.

El segundo pilar de la democracia líquida es la creación de un Parlamento virtual que deberá reemplazar el Parlamento tradicional. En realidad, la creación de este tipo de institución virtual resulta más compleja de lo que parece y, de hecho, se trata solamente de la última fase de este traspaso entre un organismo clásico a favor de uno que representa la era 4.0.

El Parlamento Virtual consentirá, siempre según la visión de los partidarios de la democracia liquida, que cada ciudadano ocupe su escaño y pueda votar, realizar propuestas o delegar su voto en los representantes que elija (por eso la importancia de la delegación del voto) a través de las nuevas tecnologías. A tal propósito y para garantizar la identidad del ciudadano y comprobar la legalidad de su voto, se utilizará el documento de identidad electrónico que entre otras opciones, incorporará funciones criptográficas de identificación y firma digital ${ }^{26}$.

Resulta evidentemente significativo investigar sobre la realización del traspaso de poder entre el Parlamento actual y el Parlamento virtual. La respuesta por los partidarios de la democracia líquida es la creación del Partido de Internet. Se trata de un partido sin ideología política. Un partido que sirve como trámite entre los

\footnotetext{
${ }^{24}$ Vid. portada principal de www.democracialiquida.org.

${ }^{25} \mathrm{http}: / /$ www.democracialiquida.org/sect/es_ES/4003/Delegaci\%C3\%B3n+de+\%20Voto.html

${ }^{26}$ Esta documentación ya se entrega en los países europeos como Francia, Italia, Alemania, Holanda.
} 
ciudadanos inscriptos y el Parlamento virtual. En el material difundido por los creadores del Parlamento virtual, se puede analizar la naturaleza de este proyecto que ya se encuentra en una fase avanzada: "nuestro partido propone ser ese caballo de Troya, que jugará al juego democrático actual, para cambiarlo desde dentro".

$\mathrm{Si}$, a través de nuestros escaños, podemos llevar a las cámaras lo que opina la gente en Internet, habremos implementado una Democracia Líquida dentro del sistema actual con la intención de crecer y que, finalmente, los partidos sean meros movimientos de opinión en el propio sistema de votación por Internet. En ese momento habremos cambiado el sistema, dicen sus ideólogos. Por lo tanto, se trata de un partido político herramienta, sin ideología propia. La afiliación es gratuita y se financia a base de donaciones voluntarias. Las cuentas son públicas y las listas para las elecciones abiertas. Al reflejar la opinión de todos los que voten a través de Internet, no tenemos una tendencia política establecida.

La democracia líquida funciona así: alguien vota y es el proxy de otros en temas ambientales, pero $X$ puede representarte en temas de educación y $Z$ en el área de salud. En cualquier momento puede retomar la representación directa de su voto, para cualquier tema y sin tener que explicar el por qué, "es poder de representación", de participación en la toma de decisiones colectivas ${ }^{27}$.

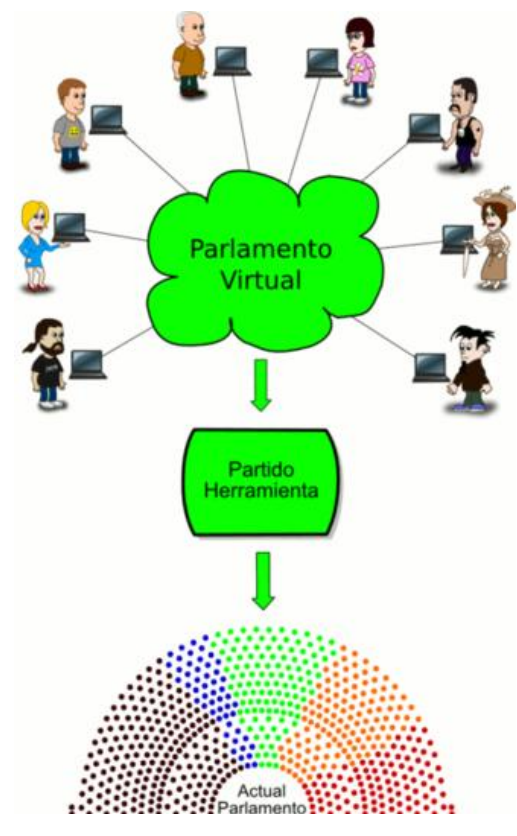

\section{Algunos ejemplos}

Las TIC, por sus características de relaciones horizontales, multiplicidad de actores, funcionamiento descentralizado y no acotado geográficamente, permiten como mínimo a nivel técnico- traspasar el sistema de representación tradicional y avanzar hacia una democracia representativa con una fuerte participación ciudadana, manteniendo el sistema de deliberación social. Así pues, facilitarían la transición de una forma de gobierno tradicional a una forma de gobierno relacional denominada governance, incorporándose a un sistema complejo que introduce la participación de varios actores en el gobierno y conlleva cambios en los roles de los

\footnotetext{
${ }^{27}$ Libre, abierto y distribuido bajo una licencia no restrictiva de M.I.T., Liquid Feedback, el programa para hacer democracia liquida está disponible para su descarga gratuita
} 
poderes públicos, en la posición que adoptan en los procesos de gobierno y en la utilización de nuevos instrumentos de gobierno.

En este marco de governance electrónica se potencian formas de participación electrónica diversas. En los años noventa encontramos en Estados Unidos y Europa algunas experiencias pioneras. Destaca Minnesota e-Democracy ${ }^{28}$ nacida en 1994 con el objetivo de informar sobre los candidatos y los programas electorales.

Actualmente, se ha ampliado a Estados Unidos y permite a los ciudadanos debatir y opinar sobre temas políticos locales, estatales o federales. En el Reino Unido destaca UK Citizens Online Democracy ${ }^{29}$ creada con el objetivo de ofrecer información y fomentar el debate entre los ciudadanos sobre temas de política general. A nivel local se desarrolla la experiencia Online Democracy in Brent ${ }^{30}$, en la que además de la consulta a la ciudadanía también se ofrecía información y se abría el debate ciudadano.

En los últimos años estas experiencias se han desarrollado enormemente. Siguiendo la variable de alcance territorial destaca Vote for the EU you want ${ }^{31}$ experiencia de ámbito supraestatal impulsada en el 2003 por la Unión Europea con el objetivo de aumentar la participación de los ciudadanos en los debates y la toma de decisiones. Permitía a los ciudadanos votar electrónicamente y emitir sus opiniones en relación con varios temas de interés para la UE.

A nivel autonómico encontramos Democracia.web ${ }^{32}$ impulsada en 1998 por la Fundación Jaume Bofill con el apoyo del Parlamento de Cataluña, con el objetivo de acercar la ciudadanía al Parlamento. Permite a los ciudadanos comunicarse con los diputados y los grupos parlamentarios, seguir las tramitaciones parlamentarias y hacer llegar propuestas de enmienda. Por otro lado destaca la Web de l'Estatut ${ }^{33}$ impulsada en el año 2004 por la Dirección General de Participación Ciudadana, con el objetivo de habilitar un espacio en Internet para el proceso de participación de reforma del Estatuto de Autonomía de Cataluña. Ofrecía información, varias herramientas de participación como foros de discusión, chats y la posibilidad de realizar preguntas y propuestas sobre la nueva ley estatutaria.

En el ámbito municipal encontramos Consensus ${ }^{34}$ experiencia que ofrece varias funcionalidades de participación ciudadana a los municipios, con tal de complementar los procesos participativos presenciales. También a nivel local, encontramos Madrid Participa ${ }^{35}$, la consulta ciudadana electrónica con más participantes potenciales (136.227 personas) realizada en España. Tiene lugar en Madrid en junio del 2004 y a través de las TIC.

Es preciso señalar que las experiencias mencionadas se encuentran dentro de la estrategia demoelitista, introduciendo cambios en el elitismo democrático sin alterar la lógica de la representación.

\footnotetext{
${ }^{28}$ www.e-democracy.org

${ }^{29} \mathrm{https}: / /$ www.mysociety.org

${ }^{30}$ Del Gobierno de Brent: https://www.brent.gov.uk

${ }^{31}$ www.evote.eu2003.org.

32 www.democracyweb.org

${ }^{33}: / /$ www.gencat.net/nouestatut

${ }^{34} \mathrm{http}: / / w w w . e-c o n s e n s u s . o r g /$

${ }^{35}$ www.madridparticipa.org
} 
El Partido de la Red es una idea y desarrollo de un grupo de emprendedores tecnológicos, comunicadores sociales, educadores y politólogos, que consideraron que el ejercicio de la actual democracia alejaba mucho al ciudadano de los ámbitos de decisión. "El Partido de la Red es un partido político que propone mejorar la democracia aprovechando las virtudes de Internet. En concreto, propone un modelo de participación ciudadana que es un híbrido de democracia directa y democracia representativa". Este partido se presentó a las elecciones legislativas de la Ciudad Autónoma de Buenos Aires en octubre de 2013 con una propuesta novedosa: de resultar ganador, su legislador electo votaría aquello que la ciudadanía le indique. Para poder llevar adelante este nuevo paradigma que proponen, desarrollaron un software al que denominaron Democracia.OS, una plataforma online, donde el $100 \%$ de la ciudadanía podrá votar sobre cada proyecto de ley. Si un ciudadano no se siente preparado para votar frente a una temática, podrá delegarle su voto a otra persona que elija ${ }^{36}$.

El partido vecinal de Los Ángeles, proporciona por red todos los datos para informarse y para participar en las decisiones municipales ${ }^{37}$.

Democracia 4.0, un partido vinculado al $15 \mathrm{M}$ que lleva esta propuesta en su programa "democraciaypunto". Propone una versión seccionada de la democracia líquida, donde solo se permite la delegación del voto en los partidos políticos, por lo que es una visión partidista. El sistema de democracia representativa con los partidos políticos seguiría funcionando, pero todo ciudadano podría ejercer su derecho a voto a través de una web gestionada por el gobierno mediante el DNle. Cuando un ciudadano ejerza el voto, le quitará la cuota de representación que le corresponde al parlamento. Si no vota, delega el voto al parlamento ${ }^{38}$.

Aunque es probable que los gobiernos formales permanezcan en la negación tanto tiempo como puedan, las aplicaciones de bloque de bloques ayudarán a estos grupos a registrarse en formas públicas, inmutables y criptográficamente seguras. Desde un punto de vista técnico, sin duda, son más transparentes -y por tanto legítimos- de lo que los gobiernos formales están ofreciendo actualmente. Liderando el camino hay una organización con sede en España: Aragón.

Aragón, en su núcleo, es una aplicación que interrumpe la banca de inversión. A través de su aplicación, sencilla y fácil de usar, cualquier persona pronto podrá registrar una organización en la cadena de bloqueo (instantáneamente, cero burocracias involucradas), administrar y vender acciones de la misma. La plataforma también incluirá sistemas de votación que utilizan la democracia líquida implementada por Democracy Earth- permitiendo que cada miembro tenga plena participación en las decisiones que se toman.

\section{La democracia directa}

\footnotetext{
${ }^{36}$ http://partidodelared.org/

${ }^{37} 8$ a8pro7vhmx.cloudfront.net/evrnc/pages/77/attachments/original/1439836939/2015-08-

20EVRNCAugust2015GeneralBoardMtgAgendaSpanish.pdf?1439836939

${ }^{38}$ Argumentan que, como el censo de electores en España es de, aproximadamente, 35 millones de votantes y el Congreso de los Diputados consta de 350 diputados, cada escaño equivale a 100.000 votos. Basándose en eso, proponen una democracia directa donde las personas pudieran votar desde su casa (voto por Internet) o desde cualquier otro centro de votación habilitado permanentemente (oficinas de correo, ayuntamientos, etc...), las votaciones del Congreso de los Diputados. Por cada ciudadano que ejerciera su derecho a voto, le restaría la cuota de representación que le pertenece al diputado, dándose el caso de que si en una votación todos los ciudadanos con derecho a voto votan, elige el pueblo y no el parlamento
} 
Para Andreas Auer ${ }^{39}$, "La democracia directa se caracteriza por el hecho de que el pueblo es un órgano del Estado que ejerce, además de las habilidades electorales tradicionales, las responsabilidades específicas en materia constitucional, convencionales, legales o administrativas. Cuando el ejercicio de estas facultades depende de la intervención o la voluntad de otro órgano del Estado, el parlamento $\mathrm{o}$ el jefe de Estado, trata de emplearlo o domesticarlo. Es independiente o propia cuando el tiempo y el tema sobre el cual las personas no toman acción que depende de la voluntad de este último, o una norma objetiva sobre la que otros órganos del Estado no tienen ninguna influencia". Así definida, la democracia directa parece no oponerse a la democracia representativa completa. Pero la definición más tradicional de democracia directa es aquella que elimina a los representantes y establece la participación directa de los ciudadanos en el gobierno de la cosa pública.

En Suiza, como en todos los países democráticos, los ciudadanos eligen a sus representantes. Pero Suiza también da a los ciudadanos la oportunidad de participar directamente en la toma de decisiones. Aunque la democracia directa no es una prerrogativa única de Suiza, el sistema suizo es probablemente el más extenso en el mundo. Los ciudadanos suizos pueden o bien hacer propuestas legislativas, o bien rechazan la legislación ya aprobada por el Parlamento. El único caso en el que el Parlamento puede tomar medidas contra este derecho es si la propuesta legislativa es inconstitucional, o si se viola el derecho internacional.

Si los votantes (por lo general un grupo de interés) se reúnen 100.000 firmas a favor de una iniciativa en particular, la cuestión debe ser sometida a votación en todo el país. En teoría, una iniciativa sólo puede ocuparse de asuntos institucionales, pero en la práctica se mantienen en muy diversas cuestiones. Recientemente se pusieron en marcha iniciativas sobre cuestiones tales como recortes en el gasto militar (rechazado) y la limitación de la población extranjera del $18 \%$ (rechazado). Las iniciativas más "originales" se centraron en la simplificación del procedimiento para la apertura de casinos (aceptados) y la prohibición de la producción y venta de absenta (recibidas).

La Unión Europea recientemente (1 de abril de 2012) introdujo un instrumento de democracia directa: el derecho de iniciativa de los ciudadanos europeos $(\mathrm{ECl})$. Al recoger un millón de firmas en al menos cinco países de la Comunidad, los ciudadanos pueden pedir a la Comisión que presente una propuesta legislativa. Por lo tanto, es una ley popular en la votación parlamentaria. Por lo tanto, es una ley popular en la votación parlamentaria. Aunque el "movimiento" o "Propuesta popular" (ya que este instrumento también se llama así) no es el más poderoso instrumento de democracia directa, ni tampoco es especialmente original, debe tenerse en cuenta algunas particularidades y la originalidad $\mathrm{ECl}$ : es el primer instrumento de democracia directa en un nivel continente. Ha permitido la recogida de firmas válidas en la red.

En Estados Unidos, como resultado del período histórico conocido como el "progresismo", que duró unas pocas décadas entre finales de 1800 y principios de 1900, y que consiste en un movimiento democrático que busca reformas para combatir la corrupción y la degeneración de los partidos políticos, en muchos estados se introdujeron instrumentos de la democracia directa. Entre ellos estaba California, el estado más poblado de Estados Unidos, donde se introdujeron

\footnotetext{
39 Profesor de Derecho Constitucional de la Universidad de Zurich y Director de Estudios y Documentación sobre Democracia Directa
} 
instrumentos de democracia directa en $1911^{40}$. En particular, el referéndum y las leyes de iniciativa popular a una consulta popular.

Las formas de democracia directa en los presentes estados de Estados Unidos son diferentes, estado por estado, y son diferentes de las de los países donde la democracia directa tiene sus raíces (como Suiza). Un resumen de las diferencias está en el texto de Bruno Kaufmann (1994) donde dice que: "Las iniciativas populares en California deambulan por el Parlamento por completo, mientras que en Suiza, una vez que las suscripciones necesarias son depositadas, se inicia un proceso muy diferente y amplio de consultas y negociaciones". Otra diferencia es el aumento de la presencia (en los Estados Unidos) del instrumento de denuncia (llamado "recuperación"), presente sólo en algunos cantones suizos. En los Estados Unidos, los instrumentos de la democracia directa son más de veinte. Por ejemplo, los siguientes estados reconocen la ley de iniciativa popular al voto popular: Alaska, Arizona, Arkansas, California, Colorado, Idaho, Maine, Massachusetts, Michigan, Missouri, Montana, Nebraska, Nevada, Dakota del Norte, Ohio, Oklahoma, Oregón, Dakota del Norte.

Los instrumentos de la democracia directa están presentes en varios estados del sur de América. El referéndum y la iniciativa popular para una elección popular están en: Bolivia, Colombia, Perú, Uruguay y Venezuela. Costa Rica prevé el referéndum y la iniciativa popular en la votación parlamentaria (una situación similar a Italia), mientras que Ecuador ofrece la iniciativa popular al voto popular, también se están desarrollando nuevas herramientas del referéndum como presupuesto participativo o iniciativas populares para la expulsión de los elegidos antes del final del mandato, referéndum revocatorio.

Mientras que en el pasado la aplicación de la democracia directa "pura" era (por razones prácticas obvias) obstaculizado por el tamaño de los Estados, en la actualidad, el discurso se volvió a abrir gracias al desarrollo de nuevas tecnologías de la comunicación. Gracias a la propagación de las computadoras y la Internet se ha revelado la capacidad técnica seria para manejar un gran "parlamento virtual" a todos los que tienen derecho (e-democracia)." La democracia directa es profesada hoy por diversos movimientos de todo el mundo (Podemos en España, Syriza en Grecia o el Movimiento 5 estrellas en Italia).

El principal teórico contemporáneo de la democracia directa (o el municipio libertario) es Murray Bookchin. Sus ideas se han realizado bajo el nombre de Confederalismo Democrático.

En el Kurdistán sirio la población se levantó primero contra el régimen de Assad y luego contra Isis (famosa es la resistencia de la ciudad de Kobane) ${ }^{41}$.

El partido on line australiano ${ }^{42}$ tiene un comienzo muy claro: "Algunas partes dan control a las organizaciones. Algunos nuevos partidos incluso la intención de que le permiten guardar, negociar, comprar y vender votos en línea. ¡NOSOTROS NO! Damos control al votante. Damos control al votante. Un voto por persona, por edición. Sin ahorro, intercambio, compra o venta de votos.

\footnotetext{
${ }^{40} \mathrm{http}: / /$ www.eduplace.com/kids/socsci/ca/books/bkd/wklyrdr/u5_article2.shtml.

41 Una cosa es "profesar" y otra "practicar" El movimento 5 stelle italiano, repárese que dice "movimiento" y no "partido" tiene un pecado de origen: el sitio del partido no está intestado al movimiento sino a dos personas el cómico Beppe Grillo y Cassaleccio. Estos, además desconocen resultados de la red, como la elección de la candidata a alcalde por Genova Marika Cassimatis, lo que provoca que el movimiento vaya a elecciones sin candidato.

${ }^{42} \mathrm{https}$ ://twitter.com/OddemocracyA.
} 


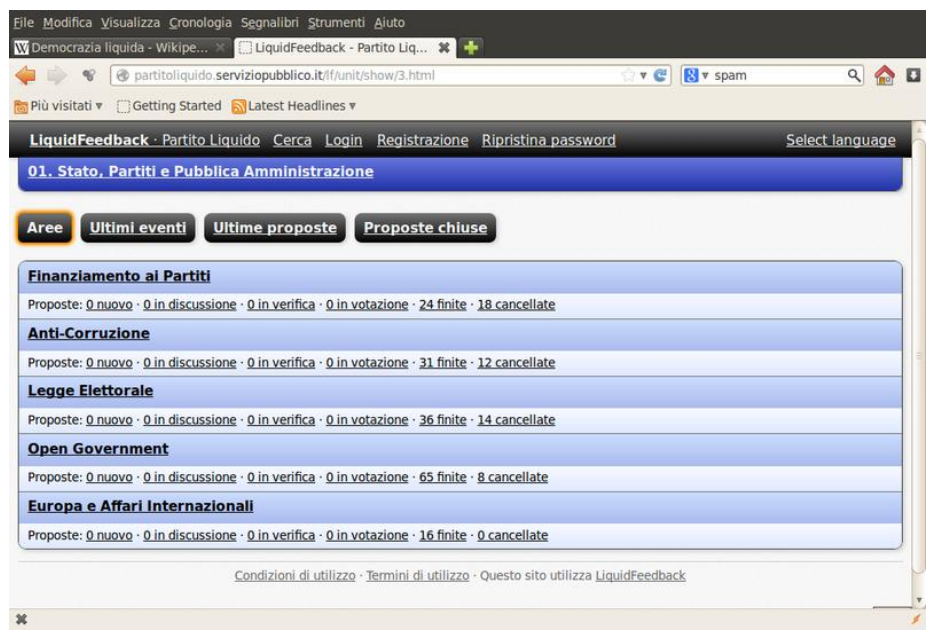

No hay política partidaria, no hay favores a los donantes, no hay influencia de MP y sigue con una clara determinación de la democracia directa ${ }^{43}$.

Partido Pirata es una etiqueta adoptada por partidos políticos en diferentes países. Los partidos piratas apoyan la defensa de los derechos civiles y sociales, democracia directa con el modelo de democracia líquida y participación ciudadana, reformas al copyright y leyes de patentes, el libre acceso al conocimiento (abrir contenidos), los bienes de uso común, la privacidad en la información, la neutralidad en la red y la protección y fomento de Internet, con un acceso igualitario a la misma, incluido el ámbito rural. Actualmente encontramos, una red de 60 partidos piratas en el mundo. Aquellos que tienen mayor participación en el gobierno en elecciones nacionales, se destacan Alemania con el $2,1 \%$ de los votos, República Checa con el $2,66 \%$, Suecia con $0,43 \%$, Islandia $5,10 \%$, Ucrania $9,0 \%$. Posee actualmente un eurodiputado.

La base de los Partidos Pirata son los derechos civiles, el derecho a la democracia directa, la participación ciudadana, la transparencia, la reforma del copyright y el sistema de patentes, el acceso a la cultura (Cultura libre), privacidad, libertad de información, educación gratuita y sanidad universal. Los Piratas defienden la neutralidad de la redy el derecho de acceso a Internet universal y sin restricciones, como condición para ello.

El 1 de enero de 2006, bajo el liderazgo de Rickard Falkvinge se fundó el primer Partido Pirata (Piratpartiet) en Suecia ${ }^{44}$.

\footnotetext{
43 DEMOCRACIA DIRECTA EN LÍNEA (Formalmente Senator Online) Los miembros del Parlamento (Senadores y Cámara de Representantes) votan de acuerdo con la clara mayoría de votos del público (USTED) al hacer leyes. Todos en la Ronda Electoral de la AEC podrán votar de forma gratuita cualquier ley o cualquier nueva ley australiana. Nuestro partido ha aprobado los requisitos de registro para la AEC y está listo para disputar la Elección Federal 2016. DEMOCRACIA A TRAVÉS DE LA TECNOLOGÍA - usando Internet podemos regresar a un sistema que refleje sus verdaderas posiciones en temas importantes. Recuperar el poder de los políticos, intereses especiales y grupos de presión y ponerlo de nuevo donde pertenece: En sus manos - ¡Ahora podemos!

${ }^{44}$ El nombre es heredado de Piratbyrån una organización que luchaba contra las leyes del copyright. Miembros del Piratbyrån había fundado previamente un tracker de BitTorrent conocido como The Pirate Bay. Piratbyrån es la versión sueca de la organización Danesa PiratGruppen, llamada así debido a que se fundó para oponerse al lobby del grupo anti-piratería AntiPiratGruppen de Dinamarca. La etiqueta "pirata", que ha sido usado por los medios de información y la industria cultural en numerosas campañas en contra de la infracción de los derechos de autor, es usada de forma reivindicativa. La ideología del Movimiento Pirata precede a la constitución de los primeros Partidos Piratas y está fuertemente influida por la ética hacker y el movimiento del software libre; ambos de varias décadas de antigüedad.
} 
La democracia directa electrónica es una forma de democracia directa en la cual Internet y otras tecnologías de comunicación electrónica se usan para mejorar la burocracia involucrada con los referendos, registrando electrónicamente los votos. Muchos partidarios piensan que también se pueden incluir en esta noción las mejoras tecnológicas al proceso deliberativo, o incluso a la gestión de gobierno para acercarla a los ciudadanos. A la democracia directa electrónica se le llama a veces $E D D$ (muchos otros nombres se usan para lo que es esencialmente el mismo concepto).

Según el concepto de aplicación moderada de la tecnología a la democracia directa, los ciudadanos tendrían el derecho de votar en asuntos legislativos ante el parlamento o el congreso, escribir nuevos proyectos legislativos y revocar representantes en cualquier etapa.

Un ejemplo contemporáneo que toma un acercamiento evolucionario a la Democracia Directa Electrónica es aquel en el que los representantes conducen referendos independientes, usando Internet u otras tecnologías de la comunicación. Este paso potencial hacia la democracia directa electrónica no requiere cambios constitucionales ya que simplemente refuerza la relación entre el elector y el elegido. El extremo sería aquel en el cual los representantes electos del pueblo en un parlamento o en un gobierno se limitasen a trasmitir a los ciudadanos aquellos proyectos que se proponen a su decisión, y hacer efectivos después los resultados de esos referendos electrónicos. Actualmente existen movimientos como Democracia Directa Digital y Partido de internet en España o Asociación Civil Eudemocracia en Argentina que abogan por dicho sistema.

Objeciones que vienen de la democracia directa se aplican a la democracia electrónica, como por ejemplo, el potencial de los gobiernos de irse hacia el populismo y la demagogia. Autores como Kampen y Snijkers (1914) han expresado el temor al populismo ya que consideran que, en todo caso, las minorías siempre sufren los costos de las elecciones insuficientes. El populismo exige mayor participación ciudadana pero no necesariamente una deliberativa.

J. Haskell apunta que los mecanismos de democracia directa no previenen de la tiranía de la mayoría, basándose en la conocida "paradoja del voto" por la cual un grupo social, aun formado por sujetos racionales y conscientes, no siempre es capaz de ordenar sus elecciones de forma coherente y por tanto, las mayorías siempre estarán compuestas por coaliciones de minorías inestables, por lo que rara vez, expresarán instrucciones políticas claras y comprehensivas, lo que, a su vez, puede llevar a concluir que el voto directo no siempre expresa la voluntad popular mejor que la decisión de los representantes. Así, según el autor, una democracia representativa podría reflejar mejor el interés público representando mayor diversidad en una sociedad plural, diversa y compleja. Por tanto, lo que sería verdaderamente necesario, es utilizar los mecanismos de democracia electrónica para crear y consolidar procedimientos que permitan revisar las decisiones políticas y escuchar a todos los intereses de la sociedad.

Por otro lado, existen objeciones más prácticas, relacionadas con la brecha digital entre aquellos con acceso a los medios de la democracia electrónica (teléfonos móviles y conexiones a Internet) y los que no los tienen, como también el costo del gasto en las innovaciones de democracia electrónica.

Tecnologías contemporáneas como listas de correo electrónico, redes p2p, software colaborativo, wikis, foros de Internet y blogs sirven como pistas y soluciones potenciales tempranas para algunos aspectos de la democracia 
electrónica; igualmente, también son muestras de algunos asuntos asociados al territorio, como la imposibilidad de sostener nuevas iniciativas o de proteger contra el robo de identidad, la sobrecarga de información o el vandalismo.

C.R. Sunstein (2009) afirma la necesidad de preguntarnos, a la hora de evaluar las nuevas tecnologías de la comunicación, de qué forma puede afectarnos como ciudadanos y no solamente preguntarnos de qué forma nos afecta como consumidores de una sociedad capitalista, sobre la base de exigirnos responder a la cuestión de qué clase de ciudadanos queremos ser, qué papel queremos jugar y en qué clase de democracia queremos vivir.

Además de críticas sobre el fondo del tema, hay también críticas formales o de seguridad, por ejemplo la facilidad con la cual las redes de computadoras son atacadas. Últimamente dos ejemplos han sido contundentes: WannaCry y Petya que son dos ransomwares ${ }^{45}$.

\section{Conclusiones}

Existen estudios de las tendencias internacionales que muestran la paralización de la curva ascendente de países que se incorporan a los sistemas democráticos a partir del 2005 y una regresión de esa curva. Otros estudios muestran formas de alarma frente a la perdida de interés, en algunos países, hacia las formas democráticas de gobierno. ¿Hay una crisis de la democracia? Parecería que no pero hay signos inquietantes de pérdida de libertad como evidencia Freedom House.

Personalmente, no estoy demasiado inquieto pero no olvido que los regímenes democráticos son raros históricamente y tienen una componente peligrosa como es la libertad que permite a mucha gente que no cree en la democracia servirse de ella para llegar al poder y luego echarla a la espalda.

Los números de los países que van abandonando las características de la democracia crecen. Venezuela y Turquía son ejemplos recientes, pero también cierto desprecio a la libertad de prensa como evidencia Donald Trump, no nos hace hablar de abandono de la democracia, pero sí son signos alarmantes que podrían repetirse y aumentar.

¿Hay crisis de la democracia representativa? Esta sí, no puede disimularse frente a los yerros catastróficos de políticos avezados con respecto a la voluntad popular y la estima creciente de la opinión pública ante manifestaciones de anti política.

¿Cómo resolverlo? Sustancialmente hay dos salidas claras: una la democracia participativa que es la democracia representativa más transparente, más deliberativa y más cercana a los votantes. Nada mejor que leer la comunicación de Alberto Dalla Via sobre el tema.

Pero, jatención! el paper de Dalla Via se intitula La democracia directa: entre la utopía y la anarquía. Así para él -aparentemente- la única salida es la reafirmación de una democracia participativa, pues descalifica la democracia directa.

\footnotetext{
${ }^{45}$ Un "ransomware" es un virus o programa malintencionado que bloquea los archivos del usuario hasta que pague un "rescate" o acceda a las peticiones de los hackers.
} 
Una vez más debo reiterar que es falsa la percepción popular que considera a la política el principal tema de la vida de los ciudadanos. Como dijimos antes a la masa le encanta "hablar" de política, pero a la hora de elegir prefiere con mucho el futbol, como espectador. Recordemos la indicación metodológica del sistemismo y en particular el sistemismo cognitivista: estamos trabajando con clasificaciones de sistemas de gobierno: democracia y autoritarismo; democracia representativa y directa; democracia participativa y liquida. Todas son construcciones mentales que tienen referentes objetivos en el mundo pero el subrayar un componente en detrimento de otro puede configurar sistemas que sean diferentes no tanto en sus componentes como en su estructura y mecanismo ${ }^{46}$.

La democracia directa requiere un compromiso y una actividad que no es usual $^{47}$ y de eso hay que tener cuenta. Es cierto que las nuevas tecnologías facilitan la participación que antes era impensable para espacios nacionales vastos y densos, inclusive para espacios supranacionales ${ }^{48}$. Es notable ver como inclusive los partidos tradicionales usan las plataformas electrónicas para hacer política ${ }^{49}$.

Las nuevas tecnologías dividen por edades a la población siendo poco el uso que se da en los miembros de la tercera edad. Pero la necesidad tiene cara de hereje y ya se están haciendo a la idea de que para usar los aviones con bajo costo en USA y Europa deben aprender a usar sus celulares para hacer el check in.

El otro tema que va subrayado es que cada vez más los ciudadanos se ocupan de "como se gobierna" y no solo "quien gobierna"; vuelve a ponerse de moda un tema que parecía caduco: "el buen gobierno" ${ }^{50}$. Norberto Bobbio se ocupó de la definición de un buen gobierno, la prueba de tres de las formas más comunes de buena gobernabilidad, heredada del clásico, por primera vez por Platón y Aristóteles. De acuerdo con el análisis típico-ideal preparado por este autor, hay "dos criterios principales para distinguir entre el buen gobierno y la mala gestión [...] La primera: el buen gobierno es el gobernante que ejerce el poder de conformidad con las leyes preestablecidas e inversamente mal gobierno es el gobierno de quien ejerce el poder sin respetar ninguna ley, sino la de su propio capricho. La segunda: el buen gobierno es el gobernante que hace uso de su poder para perseguir el bien común, el mal gobierno es el que hace uso de la facultad de perseguir su propio bien. Esto trae dos odiosas figuras típicas: el caballero que da ley en sí mismo, el autócrata en el sentido etimológico de la palabra, y el tirano que usa el poder para satisfacer sus propios placeres" (Bobbio, 1983: 237).

Las nuevas tecnologías facilitan la participación que antes era impensable para espacios nacionales vastos y densos, inclusive para espacios supranacionales $^{51}$. Es cierto que, en este momento, el uso de la tecnología para

\footnotetext{
46 Para aclarar todos estos conceptos ver MARTINO A.A., La sistémica en Mario Bunge https://es.slideshare.net/dmelop/la-sistmica-en-mario-bunge

47 Los griegos tenían a los periecos para trabajar mientras ellos se dedicaban a la res publica. Sin embargo, Aristóteles considera a la democracia el "gobierno de los pobres" pues si no trabajan por hacer política nunca serán ricos.

${ }^{48}$ Como se vio con el ejemplo último de la Unión Europea.

49 Muy interesante el análisis de campo de José SIXTO GARCíA y David ÁVILA GÓMEZ en "Presencia online y participación social de los partidos políticos españoles entre el 20D y 26J", en Question, Revista de Comunicación de la Universidad de La Plata www.question.unlp.edu.ar, El uso de las nuevas tecnologias en los cuatro partidos españoles más votados. Pdf.

${ }^{50}$ BOBBIO N. (1991), "Governo degli uomini o governo delle leggi?" in Id., Il futuro della democrazia, Einaudi, Torino; Id. (1996), Saggi sulla scienza politica in Italia, Laterza, Roma-Bari. Debo a una reflexión de Enrique ZULETA PUCEIRO, que leyó el texto la inclusión de este punto.

51 Como se vio con el ejemplo último de la Unión Europea.
} 
hacer política de representación directa es una utopía. Pero ¿Por cuánto tiempo? Hay ya partidos como los piratas ${ }^{52}$, los partidos de la Red y todos los que se basan en una e-política que están trabajando en muchas partes del mundo y con notable éxito. En el fondo creo, se irá dando una mayor participación ciudadana a través de las nuevas tecnologías primero en la administración pública, así como hoy en los bancos y poco a poco en la política ${ }^{53}$.

Sin embargo, estamos lejos de una efectiva democracia directa con medios digitales y no tanto por los medios cuanto por la cultura que debe acompañarlos y que requiere tiempo para asentarse.

Entre tanto es posible que tengamos salidas a democracias liquidas siempre y cuando los embates sobre las democracias resulten derrotados y la democracia representativa acepte el camino hacia una democracia participativa.

Bibliografía

BENJAMIN B., (1984), Strong Democracy: Participatory Politics for a New Age, University of California Press, Berkeley.

BOBBIO N. (1991), "Governo degli uomini o governo delle leggi?" in Id., I/ futuro della democrazia, Einaudi, Torino.

BOBBIO N. (1996), Saggi sulla scienza politica in Italia, Laterza, Roma-Bari.

BOBBIO N. (1983), "Il Buon governo", in Atti della Accademia Nazionale dei Lincei (adunanza solenne del 26 giugno 1981), Accademia Nazionale dei Lincei, Roma.

BOBBIO N. (1989), Estado, gobierno y sociedad: por una teoría general de la política, Editorial Fondo de Cultura Económica, México.

CÁRDENAS GARCÍA J., Democracia interna en los partidos y democracia participativa:

[En línea] www.juridicas.unam.mx/publica/librev/rev/derestas/cont/1/.../ens8.pdf

DAHL R. (1994), The New American political (dis)order: an essay. Responses by Richard M. Abrams [et al.], Institute of Governmental Studies Press, Berkely.

DALLA VIA A., La democracia directa: entre la utopía y la anarquía, Instituto de Derecho Constitucional de la Academia de Derecho y Ciencias Sociales de Buenos Aires.

ESPEJO R. y REYES A. (2016), Sistemas organizacionales. El manejo de la complejidad con el modelo de sistema viable, Bogotá, Ediciones Uniandes, Universidad de Ibagué.

Evaluación de la OCDE del sector de las nuevas empresas basadas en el conocimiento:

\footnotetext{
${ }^{52}$ Que tienen su representante en Argentina http://fmdelta903.com/blogs/beats1113/item/el-partidopirata-de-argentina-se-arma-para-paticipar-en-las-legislativas.html

${ }^{5}$ Interesante el proyecto de la Democracia Digital en Argentina: "Establecer una Democracia Directa Digital en Argentina, mediante la utilización de las nuevas tecnologias como ser Internet, computadoras, celulares, Forma de llevarlo a práctica, a través de un portal web en internet; un software de Gestión de Gobierno (Licencia GLP); y un partido político, para poder acceder al gobierno, modificar las instituciones y posteriormente prescindir de los partidos políticos en una etapa avanzada del proyecto".
} 
http://www.oecd.org/centrodemexico/Evaluaci\%C3\%B3n_de_la_OCDE_del_sector_ de_las_nuevas_empresas_\%20IMPRENTA-1.pdf

STEFAN FOA R., INGLEHART R.F., KARABCHUK T. y PONARIN E. (2017), "Conjunto-Teoría de puntos y colapso de la sociedad: el caso de Rusia", Journal of Happiness Studies, Vol. 18 (3).

STEFAN FOA R y MOUNK Y., "Los signos de la desconsolidación", en Revista Democracia, vol. 28.

FRAGA R., NuevaMayoria.com, 17 de junio de 2016.

KAMPEN y SNIJKERS (2014), The Oxford Handbook of Governance, ed. David Levi-Faur, Oxford.

KAUFMANN B. (1994), Guía para dirigir la democracia, Estocolmo.

MACAREL M.L.A. (1838), Elementos de derecho político, traducido por Félix Enciso Castrillon, II tomo, imprenta Yenes, de la calle Almudena, Madrid.

MARTINO A.A. (1978), Osservazioni sulla definizione di "dittatura", II Politico, XLII, $\mathrm{n}^{\circ}$ 2, Roma.

MARTINO A.A. (2014), Legislación y Digesto, Eudeba, Buenos Aires, 2014.

MARTINO A.A., La sistémica en Mario Bunge https://es.slideshare.net/dmelop/lasistmica-en-mario-bunge.

MCLUHAN M. (1964), Understanding Media. The Extensions of Man, The MIT Press, Cambridge, Massachusetts.

MATURANA H. y VARELA F. (1992), “¿Cómo están usando los cleptócratas extranjeros las instituciones occidentales para proteger sus ganancias mal habidas?", en The Tree of Knowledge, Boston, Londres, Shambhala.

MONUK Y. (2018), Journal of Democracy, enero.

OBAMA, Memorándum for Transparency and Open Government (21 de enero de 2009).

Open Government Partnership, 2011.

MISHRA P. (2017), La edad de la ira, Galaxia Gutemberg, Barcelona.

RAMIREZ NÁRDIZ A. (2014), "La participación como respuesta a la crisis de la representación: el rol de la democracia participativa", en Revista de Derecho Político, núm. 90.

SARTORI G. (2012), ¿Qué es la democracia?, Madrid, Taurus.

SARTORI G. (1989), Elementi di teoría política, II Mulino, Bologna.

SIXTO GARCÍA J. y ÁVILA GÓMEZ D., "Presencia online y participación social de los partidos políticos españoles entre el 20D y 26J", en Question, Revista de Comunicación de la Universidad de La Plata, www.question.unlp.edu.ar 
SUNSTEIN C.R. (2009), Republic.com 2.0, Princeton University Press.

ZANATTA L., La Nación, 28 de junio 2017.

http://www.democracialiquida.org/sect/es_ES/4003/Delegaci\%C3\%B3n+de+\%20Vot o.html

www.e-democracy.org

https://www.mysociety.org

https://www.brent.gov.uk

www.evote.eu2003.org.

www.democracyweb.org

//www.gencat.net/nouestatut

http://www.e-consensus.org/

www.madridparticipa.org

http://partidodelared.org/

8a8pro7vhmx.cloudfront.net/evrnc/pages/77/attachments/original/1439836939/201508-20EVRNCAugust2015GeneralBoardMtgAgendaSpanish.pdf?1439836939 http://www.eduplace.com/kids/socsci/ca/books/bkd/wklyrdr/u5_article2.shtml.

https://twitter.com/OddemocracyA.

http://fmdelta903.com/blogs/beats1113/item/el-partido-pirata-de-argentina-se-armapara-paticipar-en-las-legislativas.html 